\title{
CONHECIMENTO DE UNIVERSITÁRIOS DO SEXO MASCULINO SOBRE ABORTO PROVOCADO
}

\author{
THE KNOWLEDGE OF MALE UNIVERSITY STUDENTS ON INDUCED \\ ABORTION \\ EL CONOCIMIENTO QUE TIENEN LOS UNIVERSITARIOS DE SEXO \\ MASCULINO SOBRE ABORTO PROVOCADO
}

\author{
Rosineide Santana de Brito ${ }^{1}$ \\ Monaci Santos de Almeida ${ }^{2}$ \\ Bertha Cruz Enders ${ }^{3}$
}

\begin{abstract}
RESUMO:O estudo teve o objetivo de verificar o conhecimento de estudantes universitários do sexo masculino sobre o aborto provocado. A amostra foi constituida por $70 \%$ da população de cada curso da área biomédica totalizando 71 respondentes. Os dados foram coletados através de questionário elaborado a partir de pesquisas exploratórias e aplicados nos locais de aula, nos meses de agosto e outubro de 1998. Os resultados estão divididos em duas partes: a primeira caracteriza a amostra e a segunda trata das questōes relativas ao aborto provocado. A maior parte dos estudantes encontrase na faixa etária de 17-22 anos, são católicos, solteiros e são dependentes financeiramente. Um percentual representativo sabe o que é aborto provocado, os métodos utilizados e suas consequências. São de opinião contrária ao aborto e responsabilizam o casal pela decisão de deixar ou não a gravidez evoluir, em menor percentual além da mulher, outras pessoas como amigos e familiares são apontados também como responsáveis.
\end{abstract}

PALAVRAS-CHAVE: aborto, aborto provocado, estudantes universitários

\section{INTRODUÇÃO}

O trabalho em apreço trata de uma pesquisa junto a universitários com o propósito de investigar o conhecimento dos mesmos sobre o aborto provocado.

A motivação de realizar um estudo dessa natureza, deve-se a nossa vivência profissional que mostra com freqüência casos de abortos provocados em adolescentes e em mulheres adultas, realizados na maioria das vezes, em condições que não asseguram uma prática sem seqüelas, incrementando assim, os altos índices de mortalidade materna causada principalmente, por complicações hemorrágicas e infecções.

Do ponto de vista clínico, cerca de $15 \%$ das gestações resultam em abortamentos espontâneos, destes, grande parte é devido a anomalias gametogênicas ou ovulares. Baseado nesta constatação Niswander (1994), diz que o abortamento espontâneo no primeiro trimestre é um instrumento de seleção, uma função natural que melhora efetivamente a qualidade dos fetos que acabam por chegar ao termo. Entretanto existem muitos fatores maternos que podem

\footnotetext{
'Enfermeira, Mestra em enfermagem, Prof" adjunta da UFRN - Disciplina Enfermagem em Saúde Reprodutiva. CNPq

${ }^{2}$ Aluna do $8^{\circ}$ período do Curso de Graduação em Enfermagem da UFRN, Bolsista PIBICl

${ }^{3}$ Enfermeira, Doutora em Enfermagem, Prof adjunta. Coord. do Programa de Pós-Graduação em Enfermagem da UFRN.
} 
ser causas de abortos espontâneos, como por exemplo: hipotireoidismo, malformações uterinas, miomas, sinéquias intrauterina, diabetes melitus, hipertensão arterial, leucemia, púrpura trombocitopênica idiopática, anemias graves, avitaminose $\mathrm{B}$ e $\mathrm{C}$, desnutrição proteico-calórica grave, cardiopatias descompensadas, insuficiência luteal, dentre outros. Nos abortos espontâneos, a hemorragia constitui a principal causa de morbimortalidade materna. Porém, outras complicações podem decorrer da má técnica de curetagem como perfuração do útero, lesão de alças intestinais, lesão da bexiga, fistulação e infecção, principalmente se a gravidez for interrompida de forma intencional e criminosa.

Nos dias atuais, o aborto provocado é tratado como um problema de saúde pública, onde diferentes conseqüências - físicas, psicológicas, sociais - recaem sobre as mulheres, vítimas de uma sociedade que a castiga de forma isolada, como a única responsável pela gravidez. A lei brasileira é clara quando diz que o aborto é crime passivel de prisão para a mulher e para a pessoa que o comete (Oliveira, 1997). Enquanto isso, fica o homem isento das responsabilidades do seu ato sexual, respaldado pelas questões de gênero, onde homens e mulheres assumem diferentes papéis no contexto social, reservando aos dois maneiras específicas de tratar as questões da reprodução. Neste sentido, o homem é acobertado por uma sociedade que o desobriga e o pune, ao mesmo tempo, quando o coloca dentro dos preceitos de uma sociedade masculina, negando-Ihe o direito de experenciar certos sentimentos. Eximindo de suas obrigações, enquanto autor da gravidez muitas vezes não chega a tomar ciência do aborto e quando a toma goza de certos "privilégios" social e cultural que o deixa às margens dos estudos e das discussões sobre $o$ assunto.

Essas reflexões nos levam a questionar: Qual o entendimento dos universitários do sexo masculino sobre aborto provocado?

A literatura pesquisada nos revelou que inúmeros trabalhos abordando aspectos que envolvem o aborto provocado, têm sido desenvolvidos com mulheres, demonstrando uma grande escassez de estudos junto ao homem.

Assim, entendemos que um estudo dessa natureza é de suma relevância, considerando que o homem enquanto marido/companheiro, uma vez conhecendo as conseqüências do aborto provocado pode contribuir para a minimização das seqüelas do organismo da mulher, advindas dessa prática, além de diminuir seus conflitos e dividir as responsabilidades na tomada de decisão de deixar ou não uma gravidez evoluir. Diante disso, o estudo teve o objetivo de verificar o conhecimento de estudantes universitários do sexo masculino sobre aborto provocado.

\section{ASPECTOS TEÓRICOS DO ABORTO}

Os abortos na opinião de Delascio et al. (1987) são classificados segundo o quadro clínico, idade gestacional, formas e motivações. No que se refere a idade gestacional, os autores mencionam três periodos: até a $8^{\mathrm{a}}$ semana de gestação (ovular), do $3^{\circ}$ ao fim do $4^{\circ}$ mês (embrionário) e entre $04^{\circ} \mathrm{e} 06^{\circ}$ mês (fetal). Para eles, essa divisão não consulta a embriologia e atualmente considera-se apenas os abortamentos precoce e tardio.

Tratando-se de motivos que levam ao aborto, Rezende (1995)aponta aqueles ligados às causas naturais, responsáveis pelos abortamentos espontâneos e os intencionais, responsáveis pelos induzidos, sejam por interferência da gestante ou de outra pessoa.

Segundo Delascio et al. (1987), os métodos empregados para provocar o abortamento podem ser: introdução de corpos estranhos através da vagina para romper as membranas, aplicação de duchas de solução saponáceas, insuflação de ar, comprimidos vaginais de permanganato de potássio, manobras indiretas (traumas físicos e lesões corporais), agentes orais e injeçőes intra-âmnicas.

O abortamento pode apresentar várias complicações e quando o mesmo é provocado, essas complicações tomam proporções ainda maiores, principalmente no que diz respeito às 
infecções e suas conseqüências. De acordo com a exposição dos autores consultados, a maioria das possiveis complicações decorrentes do aborto provocado são devido as infecções e estas por sua vez conseqüências da utilização de métodos inadequados e invasivos por pessoas não capacitadas. "A segurança de um aborto induzido depende de quatro fatores: 0 método, a qualificação, o acesso e a qualidade dos serviços médicos para tratamentos das complicações" (Gabiatti, 1995, p.53).

As atitudes frente ao aborto provocado variam de acordo com os povos, paises, estados e épocas. Pesquisas revelam que o aborto era prática difundida na maioria dos povos da antigüidade. As mais remotas observações registradas sobre a indução do aborto foram elaboradas na China e datam do séc. XXVIII a.C. Platão sugeriu que o aborto e feticídio fossem utilizados para controle da quantidade e qualidade da população, sendo indicado para os filhos excedentes ou deficientes. Desta forma, seria mantido o equilibrio demográfico facilitando a edificação do Estado Ideal. Aristóteles elegeu o aborto como método eficaz para manter estável a demografia das cidades gregas. Sócrates aconselhava a facilitação do aborto às mulheres que o desejassem. Hipócrates estudou o quadro clínico e tratamento, como também métodos de indução do aborto, contradizendo seu próprio juramento, no qual assume o compromisso de não administrar medicamento em mulheres para provocar o aborto. "Entre os Gauleses, o aborto era considerado um direito natural do pai, que era o chefe incontestável da familia, com livre arbítrio sobre a vida ou a morte de seus filhos, nascidos ou não nascidos" (Schor; Alvarenga, 1996 , p. 4). Conforme os autores, o aborto provocado passou a ser definitivamente considerado crime com o advento do Cristianismo, tendo por base o mandamento "Não Matarás".

Septímio citado por Lisboa (1998) equiparou aborto ao crime, alegando privação do direito paterno à prole, constituindo uma ofensa ao que seria o futuro pai.

Segundo Singer, o aborto constituia prática ilegal em quase todos os paises ocidentais até 1967, com exceção da Suécia e Dinamarca. Nos Estados Unidos desde 1973 a Corte Suprema reconheceu o aborto como método legal de interromper uma gestação não desejada e admitiu que as mulheres têm o direito constitucional de abortar nos primeiros seis meses de gravidez. Os paises da Europa Ocidental, inclusive os católicos como Itália, Espanha e França, também liberalizaram leis relativas ao aborto. "A partir dos anos 60 , em virtude da evolução dos costumes sexuais, da nova posição da mulher na sociedade moderna e de outros interesses de ordem político-econômica, a tendência foi para uma crescente liberalização" (Schor; A/varenga, 1996, p. 5).

Atualmente, no Brasil, o aborto é considerado prática ilegal. O Código Penal Brasileiro (Oliveira, 1997) prevê diferentes penas como punição:

Art. 124 - detenção de 1 a 3 anos para a mulher que provocar o aborto em si mesma ou permitir que outra pessoa o provoque;

Art. 126 - reclusão de 1 a 4 anos para quem provocar aborto numa gestante com o consentimento da mesma;

Art. 125 - reclusão de 3 a 10 anos quando não houver consentimento da gestante.

Conforme o Art. 127 as penas podem ser aumentadas em um terço ou mesmo duplicadas se a gestante sofrer lesão corporal grave ou morrer em conseqüência do aborto ou dos meios empregados para provocá-lo. Entretanto, de acordo com o Art. 128 não se pune aborto provocado por médico se não há outro meio para salvar a vida da gestante, se a gravidez resulta de estupro e o aborto é consentido pela gestante ou quando incapaz, por seu representante legal (Oliveira, 1997).

A expressão "não se pune" dá margem à interpretação de que para a legislação, o aborto continua tendo status de crime, mesmo nas situações em que não haja punição. $O$ abortamento provocado não terapêutico no Brasil assume portanto uma conotação de ilegalidade, criminalidade e clandestinidade.

No que se refere aos aspectos religiosos, a incriminação do aborto pela Igreja data 
desde os tempos mais remotos. Conforme Del Priore (1995), no Brasil Colônia a Igreja estigmatizava o aborto não só por impedir o desenvolvimento de almas cristãs no céu mas também por denotar relacionamentos extraconjugais, embora o crime maior fosse o de matar o próprio filho. Desse modo, ficava a mulher que provocasse 0 aborto, sob o julgamento popular através de diferentes formas acusativas.

Hoje, o aborto continua sendo tema de calorosas discussões, nas quais vem aumentando o número de defensores de sua prática, porém a questão é controversa e ambígua.

Um dos pontos de grande discussão, parte da não comprovação da existência de uma linha divisória absolutamente nítida que separe um óvulo fecundado de um ser humano adulto. O óvulo fecundado é apenas uma célula única que em poucos dias será um aglomerado de células, mas dentro de alguns meses originará uma criança e em alguns anos um adulto, único, racional, com personalidade e autoconsciência, apto a desenvolver todo o seu potencial de ser humano. A grande dúvida é de quando se inicia a vida humana. Daí emergem duas vertentes: uma que não admite o aborto e outra que o admite, denominadas por Singer (1994), de conservadora e liberal, respectivamente.

Os conservadores defendem o processo gradual do desenvolvimento humano, afirmando que a vida começa quando inicia o desenvolvimento, ou seja, quando o óvulo é fecundado e desafiam a apontarem uma linha divisória que marque o início da vida.

De acordo com Singer (1994), alguns liberais, inclusive as leis, sugerem que se considere a viabilidade como sendo esta linha divisória. Porém, os contra-argumentos dos conservadores dizem o seguinte:

- Mesmo sendo inviável, um embrião ou feto está potencialmente caminhando para a viabilidade e já é um ser humano.

- A viabilidade depende da tecnologia médica empregada na assistência ao neonato. Assim, um feto de seis meses é viável hoje, mas não era há 30 anos; ou é viável se nascer numa cidade desenvolvida tecnologicamente e não é se nascer num vilarejo.

- O fato do embrião ou feto inviável não ter condições de sobreviver fora do útero e ser totalmente dependente de sua mãe, não dá a ela o direito de matá-lo. Se assim o fosse, também teria o direito de matar um recém-nascido, já que este é totalmente dependente de alguém.

Dentro da vertente considerada conservadora a religião tem grande representação. As igrejas protestantes, mesmo condenando o aborto, aceitam-no em caso de risco de vida para a mãe.

Para os espíritas, o aborto também é crime uma vez que impede "à alma de suportar as provas das quais o corpo deveria ser o instrumento" (Kardec, 1995, p. 171).

Dentre os argumentos anti abortistas, os mais expressivos são defendidos pela Igreja Católica, a qual condena o aborto mesmo quando há risco de vida para a mãe e em caso de estupro. Seu discurso gira em torno da santidade da vida, respeito e proteção absoluta à vida, considerando que desde o primeiro momento de sua existência, o ser humano deve ter seus direitos de pessoa reconhecidos, entre os quais o direito inviolável de todo ser inocente, à vida (CATECISMO, 1993).

\section{PROCESSO METODOLÓGICO}

O estudo em apreço é do tipo exploratório descritivo, realizado com estudantes da Universidade Federal do Rio Grande do Norte (UFRN) em Natal.

A população foi constituída por alunos do sexo masculino do primeiro período dos cursos da área biomédica: Enfermagem, Medicina, Educação Física, Zootecnia, Odontologia, Ciências Biológicas e Farmácia. A escolha da população deu-se por acreditarmos que esses alunos serão os profissionais do futuro, que provavelmente trabalharão em uma área onde a Saúde 
Reprodutiva XAborto continuará sendo motivo de preocupação dos órgäos governamentais.

Dois cursos da referida área não fizeram parte da pesquisa: o de Nutrição por não haver aluno do sexo masculino em 1998/1 e o de Fisioterapia em virtude do primeiro período só ser oferecido no segundo semestre de cada ano.

A amostra foi do tipo estratificada proporcional, representando $70 \%$ da população de cada curso, perfazendo um total de 86 alunos. Como instrumento de coleta de dados foi utilizado o questionário elaborado a partir de pesquisa exploratória, processada em etapas e através de entrevistas em profundidade. Desse processo resultaram informações das quais selecionamos as referentes ao objetivo da pesquisa. Assim, o instrumento final ficou constituído por 14 questões, na sua maioria fechadas, exceto aquelas que demandavam respostas quantitativas. $O$ questionário foi apreciado por especialistas na área e não havendo sugestões de revisão, foi submetido a pré-testagem. Nesta fase, observamos que duas questões precisavam de revisão no que se referia à redação. Uma vez redigidas, feita uma nova pré-testagem e não havendo nenhum problema, o instrumento foi considerado adequado.

A coleta de dados ocorreu nos meses de agosto e outubro de 1998, através de questionário acompanhado de uma carta, a qual dava informações sobre o estudo e exortava a colaboração dos alunos na pesquisa. Nesta fase, observamos boa aceitaçăo não só por parte dos respondentes como também dos professores que por ocasião da aplicação encontravam-se em sala de aula.

Dentre os estudantes, oito não aceitaram fazer parte da pesquisa; um com justificativa de não estar preparado para tal e os outros sem nenhuma justificativa. Vale ressaltar que tal acontecimento ocorreu com maior freqüência entre os alunos do curso de Ciências Biológicas.

Algumas dificuldades foram encontradas, o que atribuimos, primeiramente, ao longo periodo de greve das universidades federais que, não só fez alterar o cronograma inicial, como também dificultou nosso acesso aos cursos após o término da greve, uma vez que nem todos os professores foram unânimes quanto à suspensão das aulas. Sendo assim, dos cursos previstos para integrar a pesquisa, dois encerraram seu período letivo antecipadamente, nos levando a transferir a aplicação do questionário para o mês de outubro, quando teve início o segundo periodo letivo. Uma outra dificuldade encontrada foi a ausência dos universitários na sala de aula, na ocasião da coleta de dados, o que acarretou a diminuição da amostra, passando de 86 para 71 alunos.

\section{APRESENTAÇÃO E ANÁLISE DOS RESULTADOS}

Neste item são abordados os resultados obtidos através das respostas dos estudantes, os quais estão divididos em duas partes; a primeira relativa as variáveis que caracterizam a amostra e a segunda a que se refere ao aborto propriamente dito.

\section{CARACTERISTICA DA AMOSTRA}

A maioria dos estudantes encontra-se na faixa etária entre 17-22 anos (87,3\%). Afirma ter religião, recaindo o maior percentual na Católica $(77,5 \%)$. Tal resultado condiz com a realidade brasileira, onde grande parte da população admite o catolicismo como sua religião.

Com relação ao estado civil, grande proporção dos pesquisados é solteiro $(90,2 \%)$, desse $26,8 \%$ vive sozinho e $63,4 \%$ mora com os pais. Esses percentuais são representativos, considerando que a maioria dos entrevistados encontra-se numa faixa etária jovem, muitos ainda em plena adolescência. Quanto a questão de se manter ou ser mantido por alguém. $91,5 \%$ são financeiramente dependente; $76,1 \%$ declarou ser mantido pelos pais, e $4,2 \%$ por pai ou mãe. Considerando que $26,8 \%$ vive sozinho e que apenas $7,1 \%$ é independente financeiramente, constatamos que mesmo morando fora, os estudantes săo mantidos por alguém. a maioria pelos pais. Esta situação nos leva a acreditar existir um certo controle dos pais sobre 
os entrevistados, podendo exercer influências na atividade sexual dos filhos.

\section{CONHECIMENTO SOBRE O ABORTO PROVOCADO}

Quando indagados sobre se já ouviu falar em aborto, todos os entrevistados responderam afirmativamente. Porém, 2,8\% afirmou não saber o que é aborto espontâneo e 1,4\% desconhece o provocado. Esses percentuais, apesar de serem baixos, são significativos diante da problemática que envolve o aborto.

TABELA 1 - Distribuição de universitários, segundo definição de aborto provocado. Natal-RN, 1998.

\begin{tabular}{|c|c|c|}
\hline DEFINICÓES & $f$ & $\%$ \\
\hline $\begin{array}{l}\text { E o assassinato de um feto quando a gravidez é } \\
\text { indesejada }\end{array}$ & 38 & 53,5 \\
\hline É tirar o direito à vida de alguém & 34 & 47,9 \\
\hline É quando o feto morre porque a mãe tomou remédio & 26 & 36,6 \\
\hline TOTAL & 98 & 138,0 \\
\hline
\end{tabular}

Os percentuais referem-se a $100 \%$ das respostas e não a $100 \%$ dos respodentes.

A Tabela 1 nos mostra que 53,5\% dos entrevistados define o aborto provocado como 0 assassinato de um feto quando a gravidez é indesejada; $47,9 \%$ considera tirar o direito à vida de alguém e $36,6 \%$ diz que é quando o feto morre porque a mãe tomou algum remédio. Observamos que o maior percentual assemelha o aborto provocado a assassinato, enfatizando assim, o aspecto legal.

Retornando aos resultados pertinentes à religião, observamos que a maioria dos entrevistados tem religião e menos da metade evidenciou a religiosidade ao considerar a definição do aborto provocado. Esses dados confirmam estudo efetuado por Brito (1985) onde a religião ficou em plano secundário como motivo que influenciaria a decisão de deixar ou não uma gravidez evoluir. Diante disso, acreditamos que a religião não constitui o principal fator na tomada de decisão frente a gravidez indesejada.

QUADRO 1 - Métodos utilizados para provocar o aborto, segundo os entrevistados. Natal-RN, 1998.

\begin{tabular}{|c|c|c|}
\hline MÉTODOS & I. & $\%$ \\
\hline Medicamentos & 66 & 92,9 \\
\hline Espancamento & 55 & 77,5 \\
\hline Uso de fumo, álcool e maconha & 42 & 59,1 \\
\hline Curetagem & 36 & 50,7 \\
\hline Chá & 30 & 42,2 \\
\hline Susto & 27 & 38 \\
\hline Problema de saúde & 20 & 28,2 \\
\hline Outros & 7 & 9,8 \\
\hline Não satisfação de desejos & 3 & 4,2 \\
\hline
\end{tabular}


O Quadro 1 nos permite observar que um percentual elevado da amostra tem conhecimento acerca dos métodos utilizados para provocar o aborto, sendo que $92,9 \%$ dos entrevistados citou os medicamentos como método abortivo. No entanto, os dados do Tabela 1 apresentam uma incongruência pois apenas $36,6 \%$ dos respondentes definiu o aborto provocado tendo como causa o uso de medicamentos.

Neme (1995), comenta que alguns métodos empregados para indução do aborto como: introdução de corpos estranhos através da vagina, aplicação de duchas, aplicação de permanganato de potássio na vagina e manobras indiretas, estão sendo substituídas pelo uso do misoprostol (citotec), através da administração oral ou aplicação vaginal. Um estudo realizado por Costa et al (1995), constatou que $77,0 \%$ das entrevistadas utilizou o misoprostol (citotec) para indução do aborto.

Ainda referente ao Quadro 1, verificamos que $77,5 \%$ dos estudantes apontou espancamento e $38,0 \%$ o susto como métodos de indução do aborto. Rezende (1995), diz que apenas os traumatismos que causam lesões acentuadas ao útero podem provocar ou propiciar o abortamento e que mesmo grandes emoções não causam interrupção da gestação na maioria das mulheres.

$\mathrm{Na}$ amostra estudada, $89,0 \%$ relatou não ter vivenciado experiência envolvendo o aborto provocado, $11,0 \%$ declarou já ter tido experiência, deste apenas $1,8 \%$ justificou dizendo que "o pai da moça não podia saber da gravidez".

TABELA 2 - Distribuição de universitários, segundo sua forma de agir diante de uma gravidez e da possibilidade de um aborto provocado. Natal-RN, 1998.

\begin{tabular}{|c|c|c|}
\hline FORMA DE AGIR & f & $\%$ \\
\hline Aconselha a não abortar & 59 & 83,1 \\
\hline Aconselha a abortar & 03 & 4,2 \\
\hline Indiferente & 02 & 2,8 \\
\hline Não sabe & 07 & 9,9 \\
\hline TOTAL & 71 & 100,0 \\
\hline
\end{tabular}

Podemos observar na Tabela 2, que $83,1 \%$ dos estudantes são de opinião contrária ao aborto. Embora as alternativas "Indiferente" e "Não sabe" tenham alcançado percentuais relativamente baixos, totalizando $12,7 \%$ da amostra, torna-se importante uma vez que podem indicar um problema potencial mediante a atividade sexual dos jovens nos dias atuais, podendo contribuir para o aumento das seqüelas do aborto provocado.

Relativamente às responsabilidades sobre a decisão de deixar ou não a gravidez evoluir, o maior percentual recai sobre o casal, conforme as falas dos pesquisados: "O feto é parte dos dois"; "O ato sexual foi realizado pelos dois"; "Ambos fizeram filho".

A familia e os amigos aparecem também como responsáveis pelo aborto provocado sob o argumento de que os mesmos, podem dar apoio aos jovens em uma situação de gravidez indesejada.

Quanto às complicações de um aborto provocado, a amostra estudada demonstrou conhecimento, sendo que as mais citadas foram: hemorragias $(85,9 \%)$, infecções $(78,9 \%)$, morte $(76,0 \%)$ e traumas psicológicos $\quad(83.1 \%)$. Gabiatti (1995), afirma que não é unânime a opinião de que traumas psicológicos pode decorrer do aborto provocado. Estudiosos da Organização Mundial de Saúde (OMS) concluiram que não há dúvida de que a interrupção da gravidez pode precipitar reações psiconeuróticas ou mesmo psicóticas em um indivíduo susceptivel (OMS, 1995).

Quanto à questão referente à idade em que a mulher pode provocar o aborto, de acordo 
com $15,5 \%$ dos entrevistados varia de 17 a 25 anos; $40,8 \%$ respondeu qualquer idade e $31 \%$ não sabe informar.

TABELA 3 - Distribuição de universitários, segundo periodo de gestação que a mulher pode abortar. Natal-RN, 1998.

\begin{tabular}{l|c|c}
\hline PERIOOO DE GESTACSÃO QUE A MULHER & & \\
PODE ABORTAR & & \\
\hline Entre o $1^{\circ}$ e $2^{\circ}$ mês de gestação & 55 & 77,5 \\
Entre o $3^{\circ}$ e $4^{\circ}$ mês de gestação & 03 & 4,2 \\
Em qualquer periodo da gestação & 02 & 2,8 \\
Não sabe informar & 09 & 12,7 \\
Em nenhum período & 02 & 2,8 \\
\hline TOTAL & 71 & 100,0 \\
\hline
\end{tabular}

Na Tabela 3, observamos que $77,5 \%$ da amostra declarou que o periodo gestacional em que a mulher pode provocar o aborto é entre $01^{\circ} \mathrm{e} 02^{\circ}$ mês de gestação. Este resultado nos faz pensar que os universitários têm conhecimento sobre a idade gestacional em que há maior número de abortos provocado, ou sabem a relaçăo que existe entre complicações pós-aborto provocado e idade gestacional.

\section{CONSIDERAÇÕES FINAIS}

O aborto provocado é algo inerente à humanidade desde os tempos mais longinquos. Hoje, sofrendo as influências do desenvolvimento sócio-cultural é considerado problema de saúde pública, requer estudos em diferentes dimensões, principalmente entre jovens, já que esses constituem a população alvo das consequeências de um ato sexual impensado. Assim, chamar os jovens à responsabilidade de uma possivel gravidez é buscar medidas preventivas através das mudanças de comportamento, de maneira a minimizar as conseqüências de um aborto provocado.

O trabalho ora em apreço pode detectar o conhecimento de universitários sobre o tema e nos permite dizer que os mesmos têm conhecimento acerca do aborto, porém quando indagados sobre sua atitude diante de uma gravidez e da possibilidade de provocar aborto, poucos foram consistentes em sua resposta.

Portanto, diante das transformações mundiais, as discussões sobre o aborto devem ser acirradas entre os estudantes com base em conteúdos verídicos, obtidos através de investigações científicas no sentido de levar a juventude a se comprometer com ela mesma, bem como com o outro. 
ABSTRACT: The purpose of the study was to verify the knowledge of male university students regarding induced abortion. The sample was comprised of 71 male students that corresponded to $70 \%$ of the population made up of students from different health related programs at a federal university. Data was collected in August and October of 1998, by means of a questionnaire that was based on two previous exploratory studies. The respondents were 17 to 22 years old, catholic, single and financially dependent. The results demonstrated that a large percentage of male students had knowledge of what an induced abortion was and of its consequences, as well as of the methods used to induce the fetal loss. The respondents expressed a negative opinion about abortion and placed the responsibility for such a decision on the couple. They also indicated that besides the woman, other individuals, such as friends and family members beared some responsibility for the decision to end or not a pregnancy.

KEYWORDS: abortion, induced abortion, university students

RESUMEN: El objetivo del trabajo fue verificar qué conocimientos tienen los estudiantes universitarios varones sobre el aborto provocado. La muestra estuvo compuesta por $71 \%$ de estudiantes del área biomédica, lo que representó $70 \%$ de la población de alumnos en cada curso. Los datos se obtuvieron por medio de un cuestionario que se hizo con estudios de tipo exploratorio. Lo contestaron en los locales donde sucedian las clases y durante los meses de agosto a octubre de 1998. Los resultados se presentaron en dos partes: en la primera parte, se caracteriza la muestra y en la segunda, se presentan las respuestas de las cuestiones referentes al aborto provocado. La mayor parte de los estudiantes tenía entre 17 y 22 años, son católicos, solteros, y los padres los mantienen. Un porcentaje significativo sabía lo que es un aborto provocado, los métodos que se usan para hacerlo y las consecuencias. Fueron contrarios al aborto y pusieron la responsabilidad en la pareja por la decisión de dejar, o no a que evoluyese el embarazo. Además de la mujer, citan a los amigos y a los familiares también como responsables por la decisión.

PALABRAS CLAVE: aborto, aborto provocado, estudiantes universitarios

\section{REFERÊNCIAS BIBLIOGRÁFICAS}

BRITO, Rosineide Santana. Adolescente: gravidez e heterossexualidade. Conhecimento sobre concepção e contracepção. São Paulo, 1985, 246. Dissertação de Mestrado em Enfermagem Obstetrícia Social. Escola Paulista de Medicina, 1985.

IGREJA CATÓLICA. Catecismo. São Paulo: Vozes, 1993. 831p. p.591-593: O aborto.

COSTA, Cicero Ferreira Fernandes et al. Metodologia de Tratamento do Abortamento Infectado. Rev. Brasileira de Ginecologia e Obstetrícia, Rio de Janeiro. v.17, n.8, p.847-850, set. 1995

DELASCIO, Domingos et al. Sindromes hemorrágicas da gestação. 1.ed. Săo Paulo: Sarvier, 1987. Cap. 01, p.03-59: Abortamentos.

DEL PRIORE, Mary. Ao sul do corpo: condição feminina, maternidade e mentalidade no Brasil Colônia. 2.ed. Rio de Janeiro: José Olympio, 1995. Cap. 4, p.294-306: Do aborto.

GABIATTI, José Roberto Esbolatto. Fatores que influenciam a ocorrência de complicaçōes imediatas e tardias do abortamento. Jornal Brasileiro de Ginecologia. Rio de Janeiro. V.105, n.3, p.51-55, março, 1995. 
KARDEC, Allan. O livro dos Espiritos. (le livre des Esprits). Trad. de Salvador Gentile, revisăo de Elias Barbosa Araras. 92.ed. São Paulo: IDE, 1995. Cap. VII, p.165-185: Retorno à vida corporal.

LISBOA, Roberto Senise. O aborto $\theta$ os direitos da personalidade do nascituro. [s.I.], atual. 18 set. 1998. www. Fmu.br/direito/nac/11abort. html.

NEME, Bussâmara. Obstetrícia básica. São Paulo: Sarvier, 1995. Cap.123, p. 890-898: Abortamento séptico.

NISWANDER, Kenneth R.; EVANS, Arthur T. Manual de obstetrícia: diagnóstico e tratamento. 4.ed. Rio de Janeiro: MEDSI, 1994. Cap.01, p.03-28: Anticoncepção, abortamento e esterilização.

OLIVEIRA, Juarez (org.). Código Penal. 12.ed. São Paulo: Saraiva, 1997.

ORGANIZACIÓN MUNDIAL DE LA SALUD. Complicaciones de/ aborto: directrices técnicas y gestoriales de prevención y tratamento. Ginebra, 1995.

REZENDE, Jorge de. Obstetricia. 7.ed. Rio de Janeiro: Guanabara Koogan, 1995. Cap. 23, p.643-666: Abortamento.

SCHOR, Néia; ALVARENGA, Augusta T. de. O aborto: um resgate histórico e outros dados. São Paulo, atual. 14 mai. 1996. wnw. usp. br/fsp/SCHOR.htm.

SINGER, Peter. Ética prática. São Paulo: Martins Fontes, 1994.Cap.6, p.145-183: Tirar a vida: o embriāo e o feto. 